\title{
Evaluation on Impact Strength of Basalt/Kevlar Fiber Reinforced Hybrid Composites
}

\author{
V. Ramesh, P. Anand
}

\begin{abstract}
Natural and synthetic fiber reinforced hybrid composites replacing conventional metals. Because of their improved properties such as higher strength, light weight, low cost, bio-degradable and green composite. An attempt made to find the impact strength of hybrid composites. The fiber in woven mat form is added to matrix element with varying stacking sequences of symmetrical laminates. Six types of hybrid laminate composites having basalt and Kevlar fibers are the reinforcements in varying stacking sequences are produced using hand lay-up technique followed by compression molding. The impact strength of the produced composites is evaluated. Experimental results found that composite having stacking sequences of $K-B-K-B-K-B-K$ has the highest value of impact strength of 24 Joules respectively. Scanning Electron Microscope (SEM) is used to examine the morphology of fractured surface of hybrid composites during testing. SEM images revealed that hybrid composite with $K-B-K-B-K-B-K$ had less defects on its fractured surface compared to other counter parts of the hybrid composites.
\end{abstract}

Key words: Basalt fiber, Kevlar fiber, Impact strength, SEM analysis.

\section{INTRODUCTION}

Many research carried out the hybrid composites and their properties in comparison with conventional materials. Natural fiber reinforced composites become more popular among the consumers because of abundantly available, eco-friendly nature and value added raw materials for many industrial applications [1].

Davidson et al., had performed an investigation on composite material made using $12 \mathrm{wt}$. \% of jute reinforced woven fiber. They found that the quantity of fibers in the composite influenced the presence of defects like void, blow holes and delamination. Further it enhanced the strength of the material $[2,3]$.

Investigates the tensile strength of Kevlar composite prepared by hand layup method which has four layers of Kevlar laminate. The result showed that Kevlar has good tensile strength and hence can be a good alternative conventional material for many applications in engineering industries [4].

Revised Manuscript Received on October 30, 2019.

* Correspondence Author

V.Ramesh *, Research Scholar at Department of Mechanical Engineering, Vel Tech Rangarajan Dr. Sagunthala R\&D Institute of Science and Technology, Chennai, India.Email:selvaramesh27@gmail.com

P.Anand, Associate Professor at Department of Mechanical Engineering, Vel Tech Rangarajan Dr. Sagunthala R\&D Institute of Science and Technology, Chennai, India. Email: p.anand@ymail.com

(C) The Authors. Published by Blue Eyes Intelligence Engineering and Sciences Publication (BEIESP). This is an open access article under the CC BY-NC-ND license (http://creativecommons.org/licenses/by-nc-nd/4.0/)
Akil et al., in their research article studied the influence of kenaf fibers over the properties of composites containing natural and synthetic fibers. They inferred that apart from influencing the properties of the composite, kenaf fibers provide added benefits in terms of low processing cost that act as the reason for altering the synthetic fibers. It was inferred that the properties of the composites can be altered by modifying the kenaf fibers using chemical treatment. This way the natural fibers could exhibit either thermoset or thermoplastic behaviors to grant improvement in physical properties of composite material [5].Jute is the cheapest vegetal bast fibre and found in abundance in Bangladesh and India. The traditional use of jute fibre is to make hessian clothes, ropes, shopping bags and floor mats, etc. Recent research [6-9] indicates that natural fibers can very well be used as reinforcement replacing the expensive glass fibers in polymer composites. Plywood, medium density fiber boards, panel and plush doors were developed from Jute and coir based composites.

In this research work, hybrid composites containing natural fibers and synthetic fibers made up of varying stacking sequences using epoxy resin as the matrix element has been produced by hand lay-up technique followed by compression molding. Impact test and Scanning Electron Microscope (SEM) examinations are used to find the properties and defects in material.

\section{MATERIALS AND METHODS}

\section{A. Materials}

In this research work two different fibers comprising of Basalt and Kevlar were chosen as the reinforcement for the hybrid composite, while epoxy resin is chosen as the binder as well as the matrix element [10]. The mechanical properties of the reinforcement and matrix elements are shown in table 1.

Table 1. Mechanical properties of Basalt and Kevlar

\begin{tabular}{|c|c|c|c|}
\hline Properties & Basalt & Kevlar & $\begin{array}{l}\text { Epoxy } \\
\text { LY556 }\end{array}$ \\
\hline Young's modulus in GPa & 85 & 154 & 3.5 \\
\hline Tensile strength in MPa & 2900 & 2800 & 83 \\
\hline Ultimate elongation in \% & 3.15 & 2.4 & 4.2 \\
\hline Density in $\mathrm{g} / \mathrm{cm}^{3}$ & 2.67 & 1.47 & 1.15 \\
\hline Weave type & Plain & Plain & - \\
\hline
\end{tabular}




\section{Evaluation on Impact Strength of Basalt/Kevlar Fiber Reinforced Hybrid Composites}

\section{B. Fabrication of composite}

Selection of six stacking sequences its composition and layer arrangements are presented in table 2 .

Table 2. Layer arrangement and fiber volume fraction

\begin{tabular}{|c|c|c|c|}
\hline Samp & $\begin{array}{c}\text { Reinforcement } \\
\text { Arrangement } \\
\text { Basalt(B)/Kevlar }\end{array}$ & $\begin{array}{c}\text { Fiber } \\
\text { Content } \\
\text { (vol. \%) }\end{array}$ & $\begin{array}{c}\text { Resin } \\
\text { (vol. \%) } \\
\text { LY556 } \\
\text { +HY951 }\end{array}$ \\
\hline & $(\mathrm{K})$ & $\begin{array}{l}\text { Basalt/ } \\
\text { Kevlar }\end{array}$ & \\
\hline $\mathrm{U}$ & B-K-B-K-B-K-B & \multirow{6}{*}{40} & \multirow{6}{*}{60} \\
\hline $\mathrm{V}$ & K-B-K-B-K-B-K & & \\
\hline W & B-B-K-B-K-B-B & & \\
\hline$X$ & K-K-B-K-B-K-K & & \\
\hline $\mathrm{Y}$ & B-B-K-K-K-B-B & & \\
\hline Z & K-K-B-B-B-K-K & & \\
\hline
\end{tabular}

Composites are fabricated by hand layup and compression molding techniques. Care should be taken to ensure that the stacked layers of the entire composite do not exceed $4 \mathrm{~mm}$. The wooden plate gave the necessary force to press the components of the composite and spread it evenly. It was left untouched for duration of 24 hours so as to allow sufficient setting time for curing.

\section{TESTING OF COMPOSITES}

The produced composites were tested for impact properties and morphological analyses of fractured surface. Test specimens are cut as per ASTM standards

\section{A. Impact test}

The specimen for impact test was cut to ASTM A370 standard from the hybrid composites so as to meet the specifications to conduct Charpy impact test as shown in Figure 1.
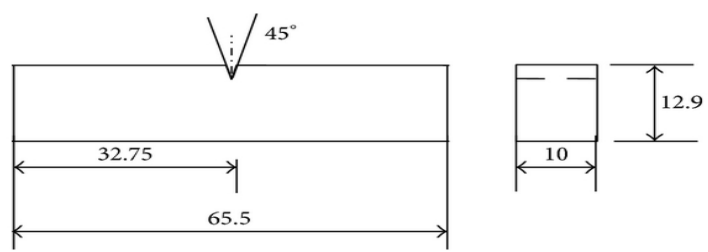

Fig.1 ASTM A370 standard dimension for impact test

A $\mathrm{V}$ notch $5 \mathrm{~mm}$ side, $2 \mathrm{~mm}$ deep and $45^{\circ}$ notch radius was cut along one of the linear edges. A $25 \mathrm{~kg}$ mass dead weight hammer was used transmit the required impact load. The reading of the test was noted from the scale in the test machine tested samples are presented in the figure 2 .

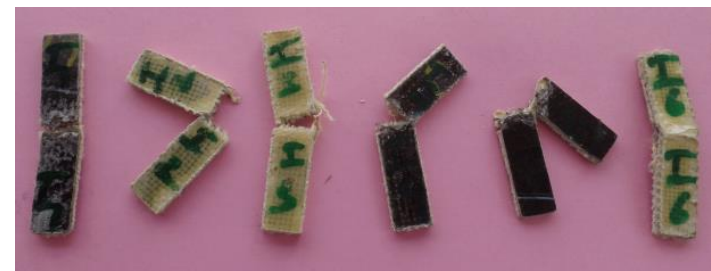

Fig.2 Impact strength tested specimen

\section{B. Morphological test}

Morphological analysis of the fractured surface of the tested specimen was made using the SEM. Each hybrid composite materials were cut to ASTM E407 standard. The Scanning Electron Microscope (Make: Hitachi Model - S3000H) which is used in the research work. It had magnification factor of $50 \mathrm{x}$ to $200 \mathrm{x}$.

\section{IV.RESULTS AND DISCUSSION}

\section{A.Impact strength}

The impact strength of the composites containing varying stacking sequences was shown in table 3 . The results obtained during the impact test and the same is plotted in Figure 3.

Table 3. Impact strength of the produced composites

\begin{tabular}{|c|c|}
\hline $\begin{array}{c}\text { Sample } \\
\text { Code }\end{array}$ & $\begin{array}{c}\text { Impact strength } \\
\text { (Joules) }\end{array}$ \\
\hline $\mathrm{U}$ & 10 \\
\hline $\mathrm{V}$ & 24 \\
\hline $\mathrm{W}$ & 6 \\
\hline $\mathrm{X}$ & 16 \\
\hline $\mathrm{Y}$ & 10 \\
\hline $\mathrm{Z}$ & 12 \\
\hline
\end{tabular}

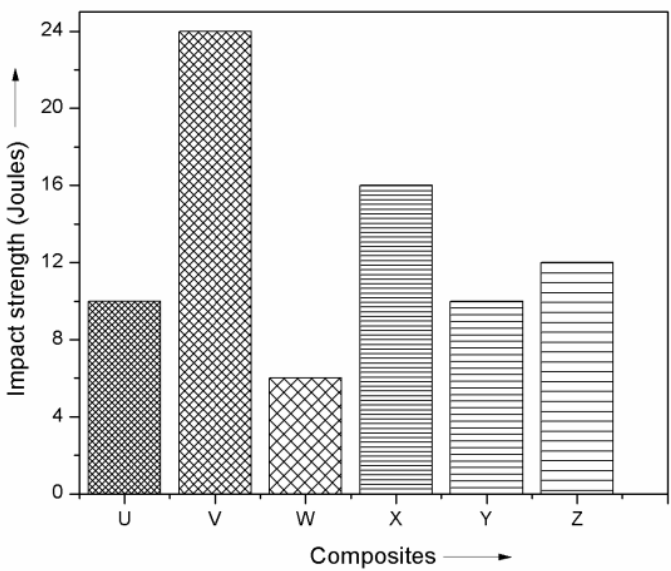

Fig. 3 Comparison of impact strength between composites

The produced hybrid composites had anisotropic behavior that showed the good impact strength. The composites containing K-B-K-B-K-B-Kwere noted to show higher impact strength of 24 Joules compared to their respective counterparts. 


\section{B. Morphological analysis}

Figure 4showed the SEM images of the hybrid composite having stacking sequences K-B-K-B-K-B-K and $\mathrm{B}-\mathrm{B}-\mathrm{K}-\mathrm{B}-\mathrm{K}-\mathrm{B}-\mathrm{B}$. The crosssectional surface along the impact on the composite containing basalt fibers revealed cleavage fracture and cone fracture. This indicated that mixed mode fracture had occurred on the composite under the influence of impact. As a result, the load was absorbed by the fiber and epoxy resin that had brittle nature.
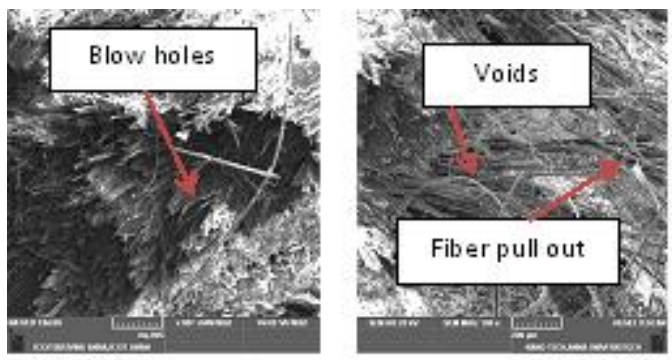

a. K-B-K-B-K-B-K b. B-B-K-B-K-B-B

Fig. 4 Comparison of SEM images after impact test

\section{CONCLUSION}

An attempt to study the influence on impact properties of the natural fiber and synthetic fiber reinforced composites. Impact test revealed that the hybrid composite had maximum strength of 24 joules of K-B-K-B-K-B-K. The morphological studies are revealing that the K-B-K-B-K-B-K. Composite had less defects compared to counter parts.

\section{REFERENCES}

1. Meddahi A, Tahar KA, Bibi M. Studies of Sisal Fiber Containing Composites. Journal of Natural Fibers 2008; 5:36-46.

2. Yang S, Chalivendra VB, Kim YK. Fracture and impact characterization of novel auxetic Kevlar/Epoxy laminated composites. Composite structures 2017; 168:120-129. doi:10.1016/j.compstruct.2017.02.034.

3. Davidson AM, Regener D. A Comparison of Aluminium-Based Metal-Matrix Composites Reinforced with Coated and Uncoated Particulate Silicon Carbide. Composites Science and Technology 2000; 60(6): 865-869.

4. Venkatasudhahar M, Velu R, Yogaraj D, Logesh K. Experimental study of moisture absorption and impact property of treated abaca/kenaf/carbon/epoxy composites. International Journal of Mechanical and Production Engineering Research and Development 2018; 291-296.

5. Akil H, Zamri MH, Osman MR. The Use of Kenaf Fibers as Reinforcements in Composites. Biofiber Reinforcement in Composite Materials2015; 24:138-161.

6. Venkatasudhahar M, Velu R, Logesh K, Ganesh R. Effect of surface modification and hybridization of natural fiber on mechanical properties of nylon epoxy hybrid composites. International Journal of Mechanical Engineering and Technology 2017; 8: 264-281.

7. Palanivel A, Veerabathiran A, Duruvasalu R, Iyyanar S, Velumayil R. Dynamic mechanical analysis and crystalline analysis of hemp fiber reinforced cellulose filled epoxy composite. Journal of Polimeros 2017; 27(4): 309-319.

8. Fasil Mohi Ud Din.Experimental Investigation on Mechanical Properties of Kevlar Fiber. International Journal of Engineering and Technology2017; 4:3466-3473.

9. Venkatasudhahar M,Velu R.Effect of drilling force on delamination of abaca/kenaf/carbon fiber reinforced hybrid composite.Current Material Science 2019; DOI: 10.2174/1874464812666190213111048.

10. Ramesh V, Anand P, Logesh K. Mechanical behavior of smart materials: A review. International journal of mechanical and production engineering research and development 2018; 75-80.

\section{AUTHORS PROFILE}

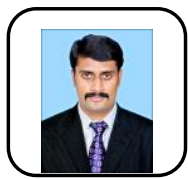

V. Ramesh received his Master's Degree from Mahendra Engineering College, Namakkal and he is currently pursuing his Doctoral Research in the area of Fiber Reinforced Composites at Vel Tech Rangarajan Dr.Sagunthala R\&D Institute of Science and Technology, Chennai, India. His research area is Hybrid Composite Materials.

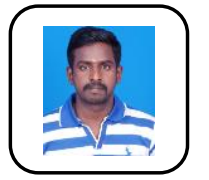

Dr.P.Anand obtained his $\mathrm{PhD}$ from Anna University Chennai in the area of Materials and Design and he is currently working as Associate Professor in Vel Tech Rangarajan Dr.Sagunthala R\&D Institute of Science and Technology, Chennai, India. His research area is Composite Materials, Design and Finite Element Analysis. 